Original article

\title{
ISOLATION AND MOLECULAR CONFIRMATION OF MYCOBACTERIUM AVIUM SUBSPECIES PARATUBERCULOSIS IN CATTLE AND BUFFALOES FROM THREE STATES OF INDIA
}

\author{
B. RAMALAKSHMI ${ }^{1,2}$, F. MUKHERJEE ${ }^{3}$, A. PRASAD ${ }^{3}$, V. S. BAHEKAR ${ }^{3}$, \\ S. K. RANA ${ }^{3}$, G. K. SHARMA ${ }^{4} \&$ V. A. SRINIVASAN ${ }^{5}$ \\ ${ }^{1}$ Research and Development Center, Indian Immunologicals Limited, Hyderabad, \\ Telangana, India; ${ }^{2}$ Department of Biotechnology, Acharya Nagarjuna University, \\ Guntur, Andhra Pradesh, India; ${ }^{3}$ National Dairy Development Board, R\&D Labora- \\ tory, Hyderabad, Telangana, India; ${ }^{4}$ National Dairy Development Board, Anand, \\ Gujarat, India; ${ }^{5}$ National Dairy Development Board, Animal Health, Gachibowli, \\ Hyderabad, Telangana, India
}

\section{Summary}

Ramalakshmi, B., F. Mukherjee, A. Prasad, V. S. Bahekar, S. K. Rana, G. K. Sharma \& V. A. Srinivasan, 2016. Isolation and molecular confirmation of Mycobacterium avium subspecies paratuberculosis in cattle and buffaloes from three states of India. Bulg. J. Vet. Med., 19, No 3, 189-199.

In a random survey for identification of Mycobacterium avium subsp paratuberculosis (MAP) in cattle and buffaloes from states of Telangana, Maharashtra and Gujarat in India, a single time point sampling of 1,008 animals was undertaken. The samples: milk $(n=605)$, faeces $(n=381)$ and necropsy/post-mortem tissues $(n=22)$ were initially processed for isolation of MAP in the MGIT BACTEC 960 system, which detected 22 out of 1,008 as MAP. All 22 samples were sub-cultured in Middlebrook 7H10 agar, Herrold's Egg Yolk medium (HYEM) and 7H9 broth supplemented with Mycobactin J. The three media showed different sensitivities in supporting the growth of field MAP strains. Only 9 out of 22 BACTEC 960 positive cultures grew on Middlebrook 7H10 agar, and 7H9 broth supplemented with Mycobactin J, while 8 out of 22 cultures grew on HYEM. Seven out of 9 positive cultures originated from milk samples from cattle, while the remaining 2 positive cultures were from necropsy and post-mortem tissues of cattle and buffalo respectively. MAP could not be isolated from faecal samples. All cultures grown on 7H10 agar, HYEM, 7H9 broth supplemented with Mycobactin $\mathrm{J}$ revealed acid fast bacilli on staining. In a recently developed in-house Real Time PCR targeting the MAP-specific insertion element ISMav2, only 8 out of the 9 field isolates were identified as MAP.

Key words: culture, Johne's disease, Mycobacterium avium subsp. paratuberculosis, Real Time PCR 
Isolation and molecular confirmation of Mycobacterium avium subspecies paratuberculosis in ....

\section{INTRODUCTION}

Mycobacterium avium subsp. paratuberculosis (MAP) is responsible for causing paratuberculosis or Johne's disease in domestic and wild ruminants (Douarre et al., 2010). MAP causes significant loss to the dairy industry in terms of decreased milk production and premature culling, increased mortality and decreased reproductive efficiency (Tiwari et al., 2005; 2008). It is an acid-fast bacillus $0.5-1.5$ $\mu \mathrm{m}$ in size and an intracellular fastidious pathogen which takes 12-16 weeks to grow (Singh et al., 2010; 2014). Animals are infected with MAP early in life by ingestion of bacterium from infected milk or colostrum, or via farm environment, but clinical symptoms appear after $2-5$ years (Eltholth et al., 2009; Anzabi \& Hanifian, 2012). MAP can remain in the field for a long time without multiplication, and such types of fields remain infectious for one year (Eslami, 2011). MAP is chiefly characterised by chronic inflammation of the intestine (Wuhib et al., 2005). It causes Crohn's disease in humans (Singh et al., 2010). Although the clear association is still not proven, it has been suggested that milk and dairy products could be possible vehicles of transmission of MAP from cattle to humans (Naser et al., 2014).

Efforts have been made in last few decades to develop protocols for the detection of MAP in clinical samples using various methods. Serology and faecal culture are commonly used for confirming paratuberculosis in the field (Collins et al., 2005; OIE, 2014), whereas molecular methods are ideal for rapid identification and confirmation of the pathogen (Lazaro et al., 2005).

The existence of Johne's disease and its serological evidence in different states in India has been documented earlier (Gupta et al., 2012; Trangadia et al., 2012;
Narnaware \& Tripathi, 2014). Despite such evidence, very few reports are available describing the isolation of MAP from cattle and buffaloes in India. A report has recently described the isolation of MAP from faecal samples $(9 / 184 ; 4.8 \%)$ from cattle and buffaloes in northern India (Chauhan et al., 2014). The present study was aimed towards a random survey to detect the direct presence of MAP in bovine and bubaline herds in some of the states in India using various cultural isolation methods, and confirmation of the isolates as MAP by a newly developed and optimised in-house real time PCR.

\section{MATERIALS AND METHODS}

\section{Samples}

A total of 1,008 samples consisting of milk $(n=605)$, faeces $(n=381)$ and postmortem tissues $(n=22)$ were included for the random survey in the present study. The samples were from different farms, fields and abattoirs from Gujarat, Maharashtra, and Telangana collected during the period from 2012 to 2014 . The tissue samples $(n=22)$ were from young male calves less than one year of age. Out of 22 samples, two were necropsy samples (mesenteric lymph node and tissue from ileo-cecal junction from calves) from a farm in Hyderabad (Telangana). The remaining 20 tissues (mesenteric lymph node) were post-mortem samples from the abattoirs located in Hyderabad (Telangana) and Mumbai (Maharashtra).The remaining 986 samples (milk and faeces) were from adult females. The species-wise and region-wide history/details of milk, faeces and tissue samples are furnished in Table 1. 
Table 1. Region-wise and species-wise distribution of field samples processed for detection of MAP

\begin{tabular}{lrcr}
\hline \multirow{2}{*}{$\begin{array}{l}\text { Geographical region/ } \\
\text { Species }\end{array}$} & Faeces & Milk & \\
\cline { 2 - 4 } & & & Tissue \\
\hline Telangana & 67 & 148 & 2 \\
Cattle & 0 & 0 & 15 \\
Buffalo & & & \\
Gujarat & 194 & 423 & 0 \\
Cattle & 120 & 34 & 0 \\
Buffalo & & 0 & 0 \\
Maharashtra & 0 & 0 & 5 \\
Cattle & 0 & 605 & 22 \\
Buffalo & 381 & & \\
\hline Total & & & \\
\hline
\end{tabular}

\section{Maintenance of Mycobacterium avium} subsp paratuberculosis reference strain

The Mycobacterium avium subsp paratuberculosis K-10 (ATCC ${ }^{\circledR}$ BAA-968 ${ }^{\mathrm{TM}}$ ) strain obtained from the American Type Culture Collection (ATCC, USA) was propagated and maintained on three different media: 7H10 agar supplemented with $10 \%$ albumin dextrose catalase (ADC) supplement, $0.05 \%$ Tween 80 (BD, USA) and $2 \mathrm{mg} / \mathrm{L}$ Mycobactin J (Synbiotics Europe, France); Herrold's egg yolk medium (HYEM) (Hi-media, India) slopes containing Mycobactin $\mathrm{J}$ $(2 \mathrm{mg} / \mathrm{L})$; or $7 \mathrm{H} 9$ broth containing $10 \%$ oleic albumin dextrose catalase (OADC) supplement, $0.05 \%$ Tween 80 , and $2 \mathrm{mg} / \mathrm{L}$ Mycobactin $\mathrm{J}$, and incubated at $37{ }^{\circ} \mathrm{C}$ for $10-12$ weeks. Maintenance of the strain was performed by continuous sub culturing in the above mentioned media at a minimum interval of 2-3 months.

\section{Processing of clinical samples prior to culture}

The milk samples were processed as described earlier by Gao et al. (2005).
Briefly, $50 \mathrm{~mL}$ of milk sample was taken in a Falcon tube, centrifuged at $3100 \times \mathrm{g}$ for $30 \mathrm{~min}$, then the supernatant was discarded and the pellet was decontaminated in $20 \mathrm{~mL}$ of $0.75 \%$ hexadecylpyridinum chloride (HPC; Sigma) for 4-5 h. After decontamination the samples were centrifuged at $1000 \times \mathrm{g}$ for $15 \mathrm{~min}$, and the pellet was dissolved in $1 \mathrm{~mL} 7 \mathrm{H} 9$ broth.

The tissue samples were processed as described by Kent \& Kubica (1985). Briefly, 4\% NaOH (Merck) was added to an equal amount of homogenised tissue sample, vortexed for $20 \mathrm{~min}$ and centrifuged at $2500 \times \mathrm{g}$ for $20 \mathrm{~min}$. The supernant was disarded and the pellet was neutralised with equal amount of phosphate buffered saline $(\mathrm{pH}$ 7.4) and centrifuged at $2500 \times \mathrm{g}$ for $15 \mathrm{~min}$. The resulting supernantant was discarded and the final pellet was resuspended in $1 \mathrm{~mL}$ of $7 \mathrm{H} 9$ broth.

Faecal samples were decontaminated as recommended by the manufacturer (Para TB MIGT $^{\mathrm{TM}}$ BACTEC960 ${ }^{\mathrm{TM}}$, Becton Dickinson, USA). Briefly, on day one, $2 \mathrm{~g}$ faeces were taken in $50 \mathrm{~mL}$ Falcon tube, to this $17.5 \mathrm{~mL}$ of sterile distlled 
water was added, vortexed and the tube was allowed to stand at room temperature for $30 \mathrm{~min}$. Then $2.5 \mathrm{~mL}$ of the supernatant was collected from the above tube and to this $2.5 \mathrm{~mL}$ of $15 \%$ bacto yeast extract (Sigma) and $0.2 \mathrm{~mL}$ of $10 \%$ sodium pyruvate (Qualigens) was added, vortexed and incubated at $35-37^{\circ} \mathrm{C}$ for 90 min. For each sample, $0.3 \mathrm{~mL}$ of $5 \%$ malachite green solution and $25 \mathrm{~mL}$ of sterile $1 / 2 \times$ Brain Heart Infusion (BHI) (BD, USA) $-0.9 \%$ HPC solution was added and incubated overnight at $35-37^{\circ} \mathrm{C}$. On day 2, the supernatant was discarded and $1 \mathrm{~mL}$ of antibiotic brew $(10 \mathrm{~mL}$ of sterile $1 / 2 \times \mathrm{BHI}+$ $40 \mu \mathrm{L}$ of $2.5 \%$ vancomycin $+40 \mu \mathrm{L}$ of $2.5 \%$ nalidixic acid $+25 \mu \mathrm{L}$ of $1 \%$ amphotericin B) was added. This suspension was incubated overnight at $35-37^{\circ} \mathrm{C}$. After incubation $0.1 \mathrm{~mL}$ of the suspension was inoculated into Para TB medium tubes (Cat. No. 245154, BD, USA).

\section{Isolation by culture}

The decontaminated sediments as described above, inoculated into Para TB medium tubes (Cat. No. 245154, BD, USA) were processed in BACTEC MGIT 960 instrument for 49 days at $37{ }^{\circ} \mathrm{C}$. Prior to inoculation the BACTEC ${ }^{\mathrm{TM}}$ MGIT $^{\mathrm{TM}}$ Para TB medium tubes (MGIT tubes) were supplemented with OADC enrichment medium (Cat. No. 245156, BD, USA), egg yolk, amphotericin B, nalidixic acid, and vancomycin (Sigma, USA) as indicated in the BD protocol. MGIT tubes prepared as described above were left at room temperature for $18-24 \mathrm{~h}$ to allow the egg yolk to equilibrate with culture medium.

The identification of MGIT tubes positive for MAP was according to the algorithm prescribed for BACTEC 960 (Becton Dickinson, USA).The MAP positive MGIT were sub-cultured. According to the diagnostic protocol, readouts of the results returned by the machine from the MGIT tubes signalling/flagging positive (audio-signal) due to the algorithm of BACTEC 960 expressed in terms of 'Growth Units' and 'Time to detection' were noted. The MGIT tubes that were detected positive were re-entered into the BACTEC 960 for confirmation of initial (first) positive signal. The results obtained after second and final audio-signals were considered as confirmatory for detection of MAP as per the BACTEC 960 protocol. The $+\mathrm{T}$ in readout indicated that the machine had detected a signal above the positive threshold value as determined by the algorithm of the instrument, while the readout $\mathrm{T}$ indicated a positive value lying on the threshold.

One tube of each of the following media: 7H10 agar supplemented with 10\% albumin dextrose catalase (ADC) supplement, $0.05 \%$ Tween 80 and $2 \mathrm{mg} / \mathrm{L}$ Mycobactin J (Synbiotics Europe, France); Herrold's egg yolk medium (HYEM) slopes containing Mycobactin J (2 mg/L) or $7 \mathrm{H} 9$ broth containing $10 \%$ oleic albumin dextrose catalase (OADC) supplement, $0.05 \%$ Tween 80 , and $2 \mathrm{mg} / \mathrm{L}$ of Mycobactin $\mathrm{J}$, were inoculated with $0.1 \mathrm{~mL}$ of culture from MGIT culture positive tubes and incubated at $37^{\circ} \mathrm{C}$ for $12-16$ weeks.

Identification of MAP from cultures by staining for acid-fast bacilli (AFB)

Heat fixed smears prepared from MGIT cultures declared positive by the BACTEC 960 system, and typical growths on $7 \mathrm{H} 10$ agar and HEYM slopes or 7H9 broth cultures showing turbidity were screened for presence of AFB organisms. The smears were examined for AFB organisms by using modified Ziehl-Neelsen and AFB fluorescent staining as per the vendor's protocol (Becton Dickinson, USA). 


\section{Identification of contaminating bacteria and fungi in MGIT cultures}

The Soybean Casein Digest Medium (SCDM) (Hi-media, India) was prepared as prescribed by the manufacturer. After the end of 49-day incubation of cultures in the MGIT BACTEC $960,0.1 \mathrm{~mL}$ of sample from each MGIT tube was inoculated in SCDM.

\section{Molecular confirmation of MAP field isolates}

The positive MGIT cultures were subcultured into $7 \mathrm{H} 9$ broth. Ten to fifteen days cultures in $7 \mathrm{H} 9$ broth were used for DNA extraction. DNA extraction was performed according to the protocol of a commercial MAP Extraction kit (Tetracore ${ }^{\circledR}$, Rockville, U.S.A).

An optimised in-house real time TaqMan PCR targeting a MAP specific ISMav2 gene recently developed in our laboratory (unpublished data) was used for confirmation of isolates as MAP. The ISMav2 was selected because of the specific diagnostic potential of the region (Strommenger et al., 2001; Startmann et al., 2002). The threshold $\mathrm{Cq}$ of $<40$ was determined as the cut-off value in the real time PCR for classifying samples as positive.

\section{Statistical analysis}

The data for 'days to detection' and 'growth units' obtained from MGIT BACTEC 960 machine readouts were subjected to statistical analysis employing Microsoft Excel software version 2010. The ' $\mathrm{T}$ ' in the 'Growth Unit' readout value was considered as 1 in this study for statistical considerations, since this number was the least readout value returned by the BACTEC 960.

\section{RESULTS}

Twenty-two out of 1,008 samples were detected as MAP by the MGIT BACTEC 960. The results of the confirmatory final readouts indicated that the mean \pm SD time to detection was $23.11 \pm 10.97$ days and the mean \pm SD growth units: 2096 \pm 5416.46 (Table 2). Only 9 out of 22 BACTEC 960 positive cultures grew on Middlebrook $7 \mathrm{H} 10$ agar, and $7 \mathrm{H} 9$ broth supplemented with Mycobactin J, while 8 out of 22 cultures grew on HYEM. Seven out of 9 positive cultures originated from milk samples from cattle, while the remaining 2 positive cultures were from necropsy and post-mortem tissues of cattle and buffalo, respectively (Table 2). MAP could not be isolated from faecal samples. All cultures grown on 7H10 agar, HYEM, 7 H9 broth supplemented with Mycobactin J revealed acid fast bacilli on staining, however only 9 out of 22 samples from MGIT were positive by AFB staining (Table 2).

It was also observed that an animal may not shed MAP simultaneously in milk and faeces (Table 3). However, when a recently developed in-house real time PCR targeting the MAP specific insertion element ISMav2 was used for confirmation, only 8 out of the 9 field isolates were identified as MAP (Table 2).

Results of sterility testing in SCDM medium indicated that 13 samples positive by MGIT BACTEC 960, but negative by AFB staining were contaminated with Gram negative rods, Gram negative cocci and sometimes Gram positive cocci.

\section{DISCUSSION}

The MGIT BACTEC 960 system has been extensively used for the isolation of mycobacteria in recent years (Hillemann et al., 2006). The present study confirms the 
Isolation and molecular confirmation of Mycobacterium avium subspecies paratuberculosis in ....

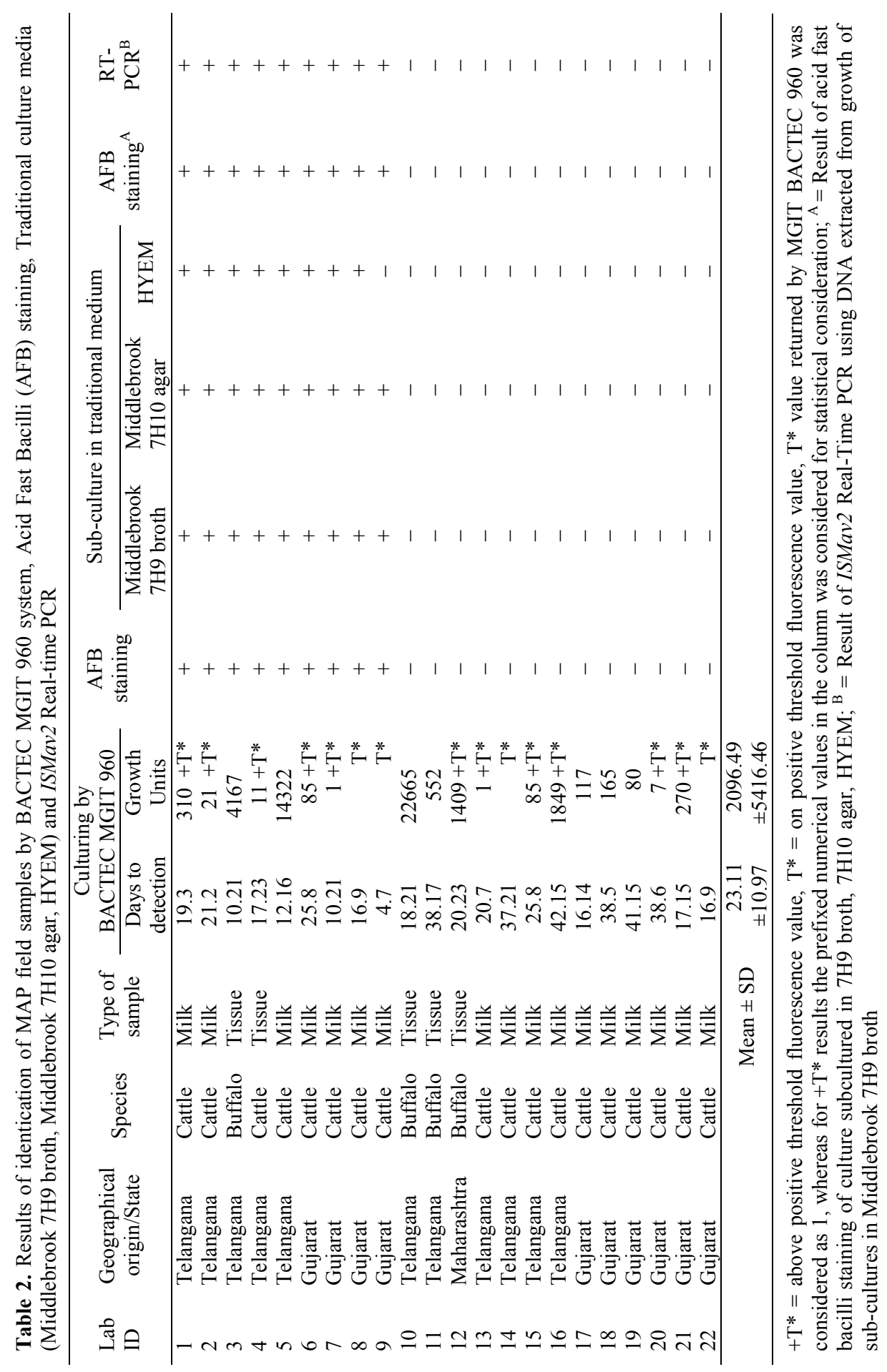


Table 3. Comparison of distribution of MAP isolated from various field samples

\begin{tabular}{llll}
\hline $\begin{array}{l}\text { Laboratory ID } \\
\text { of samples }\end{array}$ & Faecal samples & Milk samples & Tissue samples \\
\hline 1 & NA & Positive & NA \\
2 & Negative & Positive & NA \\
3 & NA & NA & Positive \\
4 & Negative & NA & Positive \\
5 & Negative & Positive & NA \\
6 & NA & Positive & NA \\
7 & NA & Positive & NA \\
8 & NA & Positive & NA \\
9 & NA & Positive & NA \\
\hline
\end{tabular}

NA - not available

utility of the MGIT BACTEC 960 culture system for quicker diagnosis of MAP by culture as compared to the traditional media. In this report, for the first time, we confirm the presence of MAP by culture in milk samples of cattle from Gujarat and Telangana employing the BACTEC MGIT 960. Out of 9 MAP field isolates recorded in this study $7(77.77 \%)$ were from unpasteurised milk samples of cattle in Gujarat and Telangana. In an earlier report MAP was isolated from $44 \%(7 / 16)$ of unpasteurised and $67 \%$ (18/27) pasteurised milk samples of cattle from states of northern India (Shankar et al., 2009). Since MAP has been associated with Crohn's disease in humans, the zoonotic implications of consumption of cattle milk infected with MAP in the regions studied in India could be of serious concern for public health.

Although this laboratory had earlier used fluorescence based commercial liquid culture system to identify an MAP isolate from faecal samples $(n=20)$ from chronically infected crossbred (as determined by Johnin test and milk and serum ELISA) dairy cows in a farm located in Hyderabad, it was unable to identify MAP from any of the 20 milk samples (unpublished results). In the study cited above the animals were over 4 years of age. We report in the current study, isolation of MAP from necropsy as well as postmortem tissues of young male beef and buffalo calves less than one year of age, thus confirming an ealier observation that animals are infected very early in life but exhibit clinical symptoms after 2-5 years (Eltholth et al., 2009; Anzabi \& Hanifian, 2012).

The detection rate varied from $2.18 \%$ to $0.79 \%$ in the different media used in this study (MGIT BACTEC 960, 7H10 agar, HYEM and 7H9 broth - all media supplemented with Mycobactin J). By employing the MGIT BACTEC 960 for identification of MAP by culture, we were able to advance the mean TTD in this study to 23.11 days post inoculation; and in one occasion the confirmation was recorded as early as 4.7 days. These results indicated the obvious diagnostic advantage of the BACTEC 960 fluorescence based liquid culture over tradition culture media such as HYEM, 7H10 agar or 7H9 broth with respect to turn around time. From unpublished data, the faecal isolate was detected 19 days post inoculation in the MGIT 960 system. The TTD is crucial for diagnosis. In an earlier study, positive detection of MAP on HYEM was ob- 
served between 45 to 600 days (Shankar et al., 2009). The liquid culture media have been favoured for the cultivation of MAP from clinical samples because of their greater analytical sensitivities than solid media (Whittington, 2009). In the current study MAP could not be detected in any of the faecal samples. This may have been due to the low sensitivity of faecal culture or a result of intermittent shedding of MAP in faecal samples (Laurin et al., 2014; Kauffman et al., 2014). The success of culture from faeces is clearly related to the sufficient number of MAP being shed from the intestinal lesions (Vansnick et al., 2002). Linked to these observations, the single point sampling could have contributed to the nonrecovery of MAP from faecal samples in this study. Although the number of observations was small, at least in three cases, MAP could be isolated from milk but not from the faeces of the same animal, indicating that at one point in time, MAP may not be shed simultaneously in the faeces and milk.

In this study we found that 13 out of 22 samples identified as MAP positive cultures by MGIT BACTEC 960 were contaminated by other bacteria, even when recommended decontamination protocols were performed. This observation emphasises that meticulous care is essential during collection of field samples while ensuring the adherence to far more stringent aseptic conditions. It also appears that decontamination protocols practiced in this study need further modifications to suit the local conditions for recovery of pure MAP cultures from field samples. The degree of contamination in the 13 MGIT BACTEC 960 positive cultures may have affected the AFB staining results.

Molecular confirmation of MAP isolates employing the most widely used
IS900 gene target has been recommended (Donaghy et al., 2010; Selim et al., 2013). However, there are evidences of false positive results using IS900 gene target by PCR (Cousins et al., 2000; Harris \& Barletta, 2001; Bolske et al., 2002; Englund et al., 2002). Alternatively, the MAP specific genetic element ISMav2 found in at least three copies have been evaluated to improve the specificity and reliability of detection of MAP by PCR (Strommenger et al., 2001; Stratmann et al., 2002; Schonebrucher et al., 2008; Selim et al., 2013). We also experienced the nonspecificity of IS900 PCR while optimising an in-house Real Time TaqMan PCR and found that the ISMav2 based TaqMan Real Time PCR was specific for the identification of MAP (unpublished data). We therefore used the ISMav2 in-house Real Time TaqMan PCR for confirmation of the 9 MAP field isolates using DNA extracts from sub-cultures in Middlebrook $7 \mathrm{H} 9$ broth and found that it had a sensitivity of $88.88 \%$.

\section{CONCLUSION}

The sensitivity of detection of MAP from field samples by the fluorescent based liquid culture system (BACTEC MGIT 960) $(2.18 \%)$ was just slightly better than that of traditional media ( 0.789 to $0.89 \%)$. The most obvious advantage of employing the BACTEC MGIT 960 is the quicker identification of MAP from field samples (Mean TTD $=23.11$ days post inoculation) compared to the traditional media. Together, the strategy of adopting BACTEC MGIT 960 for intial cultures followed by sub-culturing of positive isolates in Middlebrook 7H9 broth, and molecular confirmation of sub-cultures using the Real time ISMav2 PCR can be suggested as a robust and specific MAP iden- 
tification system. The AFB staining of cultures grown in MGIT 960 or traditional media seems to have a very significant role in this strategy as it provides specificity to morphological identification. Multiple time point sampling rather than the single time point sampling that was employed in this study may further aid in improving the efficacy of the adopted strategy.

\section{ACKNOWLEDGEMENTS}

The authors are grateful to the management of the National Dairy Development Board (NDDB), Anand for providing the facilities to carry out this work. The author B.Rama Lakshmi expresses her gratitude to the Indian Immunologicals Limited, Hyderabad for providing the opportunities to work on the above topic with respect to partial fulfillment for her $\mathrm{PhD}$ thesis.

\section{REFERENCES}

Anzabi, Y. \& S. Hanifian, 2012. Detection of Mycobacterium avium subsp paratuberculosis in pasteurized milk by IS900 PCR and culture method. African Journal of Microbiology Research, 6, 1453-1456.

Bolske, G., J. Englund, K. E. Johansson \& M. H. Konigsson, 2002. False positive $\mathrm{Myco}$ bacterium avium subsp paratuberculosis IS900 PCR and its diagnostic implications. In: Proceedings of Seventh International colloquium on paratuberculosis. http: //www.paratuberculosis.info/images/stories/pdfs/56 (18 November 2015 date last accessed).

Chauhan, D. S., A. Singh, A. V. Singh \& P. K. Singh, 2014. Conventional detection and molecular epidemiology of paratuberculosis in farmer herd's of domestic livestock of north India. In: $12^{\text {th }}$ International colloquium on paratuberculosis proceedings (Abstracts), Parma, Italy. http://www. paratuberculosis.info/images/proc12/062. pdf (18 November 2015 date last accessed).

Collins, M. T., S. J. Wells, K. R. Petrini, J. E. Collins, R. D. Schultz \& R. H. Whitlock, 2005. Evaluation of five antibody detection tests for diagnosis of bovine paratuberculosis. Clinical and Diagnostic Laboratory Immunology, 12, 685-692.

Cousins, D. V, R. Whittington, I. Marsh, A. Masters, R. J. Evans \& P. Kluver, 2000. Mycobacteria distinct from Mycobacterium avium subsp paratuberculosis isolated from the faces of ruminants possess IS900 like sequences detectable IS900 polymerase chain reaction implications for diagnosis. Molecular and Cellular Probe, 13, 431-442.

Donaghy, J. A, J. Johnson \& M. T. Rowe, 2010. Detection of Mycobacterium avium subsp paratuberculosis in cheese, milk powder and milk using IS900 and f57 based PCR assays. Journal of Applied Microbiology, 110, 479-489.

Douarre, P. E., W. Cashman, J. Buckley, A. Coffey \& J. M. O. Mahony, 2010. Isolation and detection of Mycobacterium avium subsp paratuberculosis (MAP) from cattle in Ireland using both traditional culture and molecular based methods. Gut Pathogens, 2, 11.

Eltholth, M. M., V. R. Marsh, S. Van Winden \& F. J. Guitian, 2009. Contamination of food products with Mycobacterium avium paratuberculosis: A systematic review. Journal of Applied Microbiology, 107, 1061-1071.

Englund, S., G. Bolske \& K. E. Johansson, 2002. An IS900-like sequence found in a Mycobacterium sp. other than Mycobacterium avium subsp paratuberculosis. FEMS Microbiology Letters, 209, 267-271.

Eslami, M., 2011. Comparison of culture and PCR methods for the detection of Johne's disease in milk samples. Journal of Animal and Veterinary Advances, 10, 614-618.

Gao, A., J. Odumeru, M. Raymond \& L. Mutharia, 2005. Development of improved method for isolation of Mycobacterium 
Isolation and molecular confirmation of Mycobacterium avium subspecies paratuberculosis in ....

avium subsp. Paratuberculosis from bulk tank milk: Effect of age of milk, centrifugation, and decontamination. Canadian Journal of Veterinary Research, 69, 81-87.

Gupta, A., S. M. Rani, P. Agrawal \& P. K. Gupta, 2012. Sero-prevalence of paratuberculosis (Johne's disease) in cattle population of South-Western Bangalore using ELISA kit. Open Journal of Veterinary Medicine, 2, 196-200.

Harris, N. B. \& R. G. Barletta, 2001. Mycobacterium avium subsp. paratuberculosis in Veterinary Medicine. Clinical Microbiology Reviews, 14, 489-512.

Hillemann, D., E. Richter \& S. Rusch-Gerdes, 2006. Use of the BACTEC Mycobacteria Growth Indicator Tube 960 automated system for recovery of mycobacteria from 9,558 extra pulmonary specimens, including urine samples. Journal of Clinical Microbiology, 44, 4014-4017.

OIE Terrestrial Manual 2014, Chapter 2.1.11Paratuberculosis (Johne's disease). http:// www.oie.int/fileadmin/Home/fr/Health_sta ndards/tahm/2.01.11_PARATB.pdf (18 November 2015 date last accessed).

Kauffman, N., O. Koren, A. Shwimmer, Z. Baider, F. Mor, K. Grinberg \& D. Elad, 2014. Assessing the fecal shedding consistency of Mycobacterium avium subsp paratuberculosis in dairy cows by qPCR: A preliminary study. Israel Journal of Veterinary Medicine, 69, 136-140.

Kent, P. T. \& G. P. W. Kubica, 1985. Public Health Mycobacteriology. A Guide for the Level III Laboratory. Atlanta: Centers for Disease Control, pp. 21-44.

Laurin, E., S. McKenna, M. Chaffer \& G. Keefe, 2014. Fecal shedding patterns of Mycobacterium avium subsp paratuberculosis in Johne's infected dairy cows. In: $12^{\text {th }}$ International Colloquium on Paratuberculosis Proceedings (Abstracts), Parma, Italy. http://www.paratuberculosis. info/images/proc12/008.pdf (18 November 2015 date last accessed).

Lazaro, R. D., D. M. Agostino, A. Herrewegh, M. Pla, N. Cook \& J. Ikonomopoulos,
2005. Real-time PCR-based methods for detection of Mycobacterium avium subsp. paratuberculosis in water and milk. International Journal of Food Microbiology, 101, 93-104.

Narnaware, S. \& B. N. Tripathi, 2014. Seroprevalence of bovine paratuberculosis in organized and unorganized farms in India by an indigenous and a commercial ELISA. In: $12^{\text {th }}$ International Colloquium on Paratuberculosis Proceedings (Abstracts), Parma, Italy. www.paratuberculosis.info/images/proc12/296.pdf (18 November 2015 date last accessed).

Naser, S. A., S. R. Sagramsingh, A. S. Naser \& S. Thanigachalam, 2014. Mycobacterium avium subspecies paratuberculosis causes Crohn's disease in some inflammatory bowel disease patients. World Journal of Gastroenterology, 20, 7403-7415.

Schonebruchner, H., A. Abdulmawjood, K. Failing \& M. Bulte, 2008. New Triplex Real-Time PCR assay for detection of $M y$ cobacterium avium subsp paratuberculosis in bovine feces. Applied and Environmental Microbiology, 74, 2751-2758.

Selim, A., M. El-haig, E. S. Galila \& W. Gaede, 2013. Direct detection of Mycobacterium avium subsp paratuberculosis in bovine milk by multiplex real time PCR. Animal Science Papers and Reports, 31, 291-302.

Shankar, H., S. V. Singh, P. K. Singh, A. V. Singh, J. S. Sohal \& R. J. Greenstein, 2009. Presence, characterization, and genotype profiles of Mycobacterium avium subsp paratuberculosis from unpasteurized individual and pooled milk, commercial pasteurized milk, and milk products in India by culture, PCR, and PCR-REA methods. International Journal of Infectious Diseases, 14, 121-126.

Singh, A. V., S. V. Singh, P. K. Singh \& J. S. Sohal, 2010. Is Mycobacterium avium subsp. paratuberculosis, the cause of Johne's disease in animals, a good candidate for Crohn's disease in man? Indian Journal of Gastroenterology, 29, 53-58. 
Singh, S. V., K. Naveen, J. S. Sohal, A. V. Singh, P. V. Singh, N. S. Agarawal, S. Gupta, K. K. Chaubey, R. Deb, K. Dhama \& K. D. Rawat, 2014. First mass screening of the human population to estimate the bioload of Mycobacterium avium subsp paratuberculosis in North India. Journal of Public Health and Epidemiology, 6, 20 29.

Stratmann, J., B. Strommenger, K. Stevenson \& G. F. Gerlach, 2002. Development of a peptide-mediated capture PCR for detection of Mycobacterium avium subsp paratuberculosis in milk. Journal of Clinical Microbiology, 40, 4244-4250.

Strommenger, B., K. Stevenson \& G. F. Gerlach, 2001. Isolation and diagnostic potential of ISMav2, a novel insertion sequencelike element from Mycobacterium avium subspecies paratuberculosis. FEMS Microbiology Letters, 196, 31-37.

Tiwari, A., J. A.Vanleeuwen, I. R .Dohoo, G. P. Keefe \& A. Weersink, 2008. Estimate of the direct production losses in Canadian dairy herds with subclinical Mycobacterium avium subspecies paratuberculosis infection. Canadian Veterinary Journal, 49, 569-576.

Tiwari, A., J. A. Vanleeuwen, I. R. Dohoo, H. Stryhn, G. P. Keefe \& J. P. Haddad, 2005. Effects of seropositivity for bovine leukemia virus, bovine viral diarrhoea virus, Mycobacterium avium subsp paratuberculosis, and Neospora caninum on culling in dairy cattle in four Canadian provinces. Veterinary Microbiology, 109, 147-158.

Trangadia, B. J., S. K. Rana, K. Nagmani \& V. A. Srinivasan, 2012. Serological investigation of bovine brucellosis, Johne's disease and infectious bovine rhinotracheitis in two states of India. Journal of Advanced Veterinary Research, 2, 38-41.
Vansnick, E., F. Vercammen, L. Bauwens, D. Haese \& N. D. Geysen, 2002. Preliminary results of a survey for Johne's disease in the Antwerp zoo. In: Proceedings of Seventh International colloquium on paratuberculosis. http://www.paratuberculosis. info/images/stories/pdfs/105 (18 November 2015 date last accessed).

Whittington, R. J., 2009. Factors affecting isolation and identification of Mycobacterium avium subsp paratuberculosis from fecal and tissue samples in a liquid culture system. Journal of Clinical Microbiology, 47, 614-622.

Wuhib, Y. A., P. Svastova, P. Roubal, M. Bartos \& I. Pavlik, 2005. Mycobacterium avium subspecies paratuberculosis cultured from locally and commercially pasteurized cow's milk in the Czech Republic. Applied and Environmental Microbiology, 71, 1210-1214.

Paper received 22.06.2015; accepted for publication 25.09.2015

\section{Correspondence:}

Dr. V.A. Srinivasan, Advisor (Animal Health), National Dairy Development Board, 33, Telecom Nagar, Gachibowli, Hyderabad 500032, INDIA.

Tel.: +91 0423000446

Fax: +91 (0) 2692260157

e-mail: srinivasanva1948@gmail.com 